\title{
B16 - DESENVOLVIMENTO DE SISTEMA DE EXPRESSÃO EM PlATAFORMA DE CÉlula EUCARIOTA PARA A PRODUÇÃo DE ANTICORPOS MONOCLONAIS RECOMBINANTES
}

Luis Vidal Conde ${ }^{1}$, Anna Erika Vieira de Araújo ${ }^{1}$, Lucas de Almeida Machado ${ }^{1}$, Priscila Muniz da $\mathrm{Paz}^{2}$, Hilton Jorge Nascimento ${ }^{2}$, Jose Godinho da Silva Junior ${ }^{2}$, José Procópio Moreno Senna ${ }^{1}{ }^{1}$

Fiocruz, Instituto de Tecnologia em Imunobiológicos Bio-Manguinhos, Vice-diretoria de Desenvolvimento Tecnológico (VDTEC), Laboratório de Tecnologia Recombinante (LATER), Programa de Biofármacos. ${ }^{2}$ Laboratório de Macromoléculas (LAMAM).

INTRODUÇÃO: A tecnologia de hibridomas (Köhler e Milstein, 1975) foi muito utilizada nas últimas décadas para produzir anticorpos monoclonais (AcMs) a partir de clones originados da fusão entre células B murinas e células de mieloma. Porém, este técnica apresenta limitações para a produção de AcMs para uso terapêutico, principalmente pela resposta imune do hospedeiro contra as imunoglobulinas murinas. Uma alternativa consiste em produzir anticorpos recombinantes (quimeras ou humanizados) em células eucariotas. Para o estabelecimento deste sistema, utilizou-se como modelo um anticorpo monoclonal capaz de reconhecer e neutralizar cepas de Staphylococcus aureus resistentes a meticilina (MRSA).

OBJETIVO: Desenvolver um sistema de expressão de anticorpos monoclonais recombinantes em plataforma de célula eucariota empregando como modelo anticorpos monoclonais anti-MRSA.

METODOLOGIA: A partir do RNA de um hibridoma murino produtor de anticorpo anti-MRSA (desenvolvido previamente no laboratório), foram sintetizadas as sequências de DNA codificante das regiões variáveis de IgG (VHH -variable heavy chain e VLH variable light chain). As sequências foram clonadas em plasmídeos (pAG4622 e pAH4604) que permitem expressar as regiões variáveis clonadas junto com regiões constantes de IgG1, sob o controle de um promotor de cadeia pesada murino. Células de mieloma murino (NS0) foram transfectadas por eletroporação e semeadas em placas de 96 poços, dentre os quais foram selecionados os poços com colônias únicas e resistentes a altas concentrações de L-histidinol. Os clones com maior concentração de IgG $_{1}$ (ELISA) nos sobrenadantes de cultivos foram selecionados para gerar um banco celular de trabalho 
e posteriormente re-avaliados em garrafas T25 (batelada simples) usando meio DMEM LG/F12 $10 \%$ SFB para seleção do melhor clone produtor de $\operatorname{IgG}_{1}$. A afinidade do anticorpo pela bactéria foi avaliada por ensaio do tipo ELISA indireto. O anticorpo foi purificado a partir de sobrenadantes de cultivo em sistemas estáticos T175 por cromatografia de afinidade à proteína $\mathrm{A}$ (MabSelectSure ${ }^{\mathrm{TM}}$ - GE) e concentrado por unidades filtrantes Amicon ${ }^{\circledR}$ MWCO $10 \mathrm{kDa}$. Amostras de anticorpo purificado foram submetidas à análise por eletroforese em gel de poliacrilamida (SDS-PAGE) e focalização isoelétrica (IEF - PAGE).

RESULTADOS: Foram analisados 60 clones com colônia única e resistentes a Lhistidinol, dos quais 10 apresentaram títulos de $\operatorname{IgG}_{1}$ acima de $100 \mathrm{ng} \mathrm{mL}^{-1}$. Todos os clones apresentaram afinidade pelo alvo, entre estes se selecionou o melhor clone produtor (K4F2) com título de $\mathrm{IgG}_{1}$ de $3422 \pm 717 \mathrm{ng} \mathrm{mL}^{-1}$. O anticorpo purificado apresentou um peso molecular de $149 \mathrm{kDa}$ e 2 isoformas com pIs 8,64 e 8,57.

CONCLUSÃO: O sistema de expressão empregando célula eucariota possibilitou obter um clone NS0 produtor de anticorpo anti-MRSA em sistemas estáticos e purificá-lo por cromatografia de afinidade. $\mathrm{O}$ anticorpo demonstrou ter afinidade pela proteína alvo o que permitirá avaliar a eficácia terapêutica em ensaios de neutralização in vivo e in vitro. 